for

\title{
Digenite Nanosheets Synthesized by Thermolysis of Layered Copper-Alkanethiolate Frameworks
}

\author{
Whitney Bryks, Eduardo Lupi, Charles Ngo and Andrea R. Tao* \\ Department of NanoEngineering, University of California, San Diego, 9500 Gilman Dr. MC 0448, \\ La Jolla, California 92039-0448, United States
}

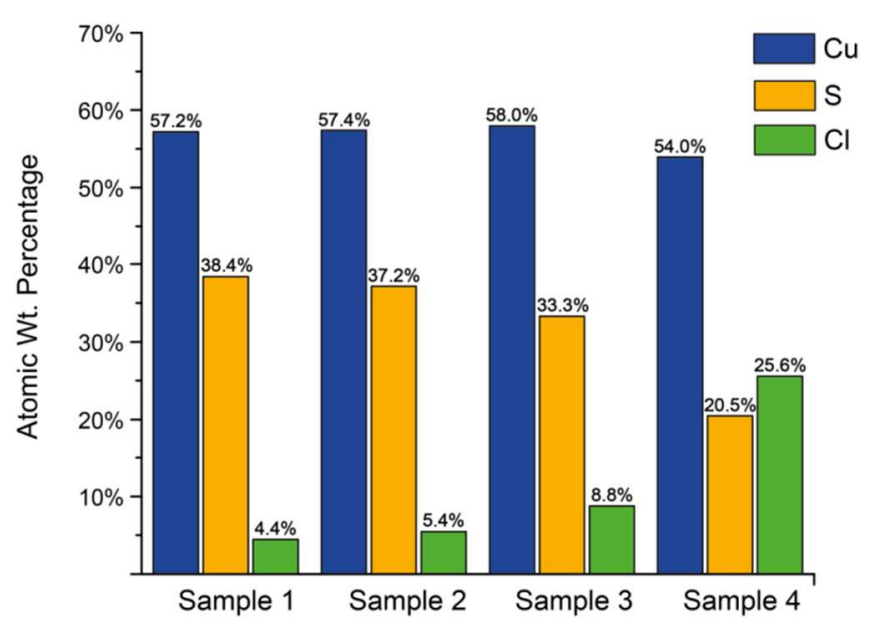

Figure S1. EDX of $\mathrm{Cu}_{2-\mathrm{X}} \mathrm{S}$ products generated from precursor in which [Cl] increases for the series. Samples 1-4 correspond to samples shown in Figure $4 \mathrm{~b}$-e respectively. $\mathrm{Cl}^{-}$content increases at the expense of $\mathrm{S}$, and consequently may be intercalating into $\mathrm{S}$ positions. Charge neutrality might be maintained due to the preponderance of $S$ existing as $\mathrm{S}_{2}{ }^{2-}$ dimers rather than $\mathrm{S}^{2-}$. 


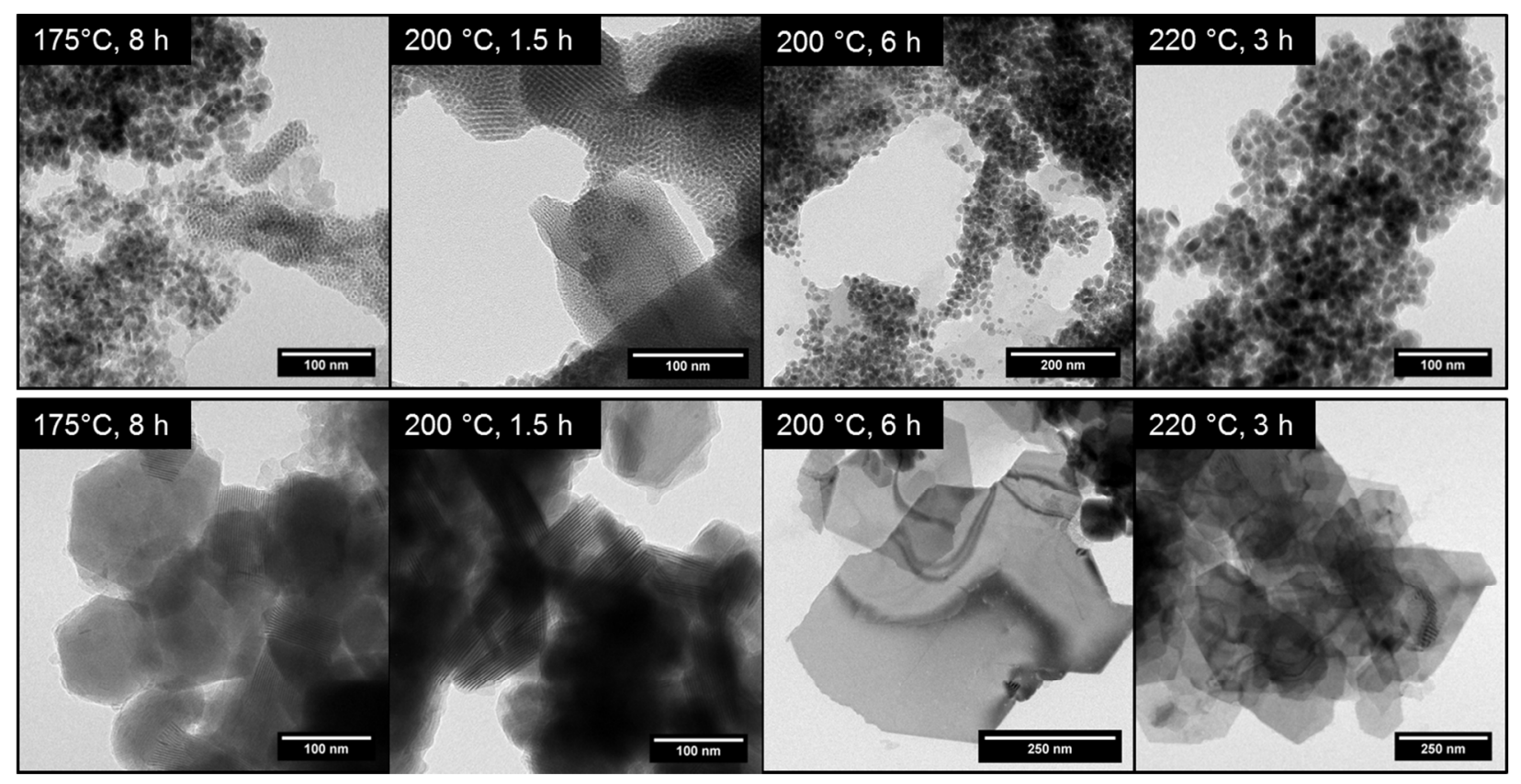

Figure S2. Top row: TEM images of $\mathrm{Cu}_{2-x} \mathrm{~S}$ nanoparticles after varying thermolysis conditions, demonstrating the propensity for small nanoparticle formation in the range of 175 to $220^{\circ} \mathrm{C}$. Bottom row: TEM images of $\mathrm{Cu}_{9} \mathrm{~S}_{5}$ nanosheets after varying thermolysis conditions, demonstrating the propensity for the $\mathrm{Cl}^{-}$bearing precursor to form the nanosheet structure in the range of 175 to $220^{\circ} \mathrm{C}$. 

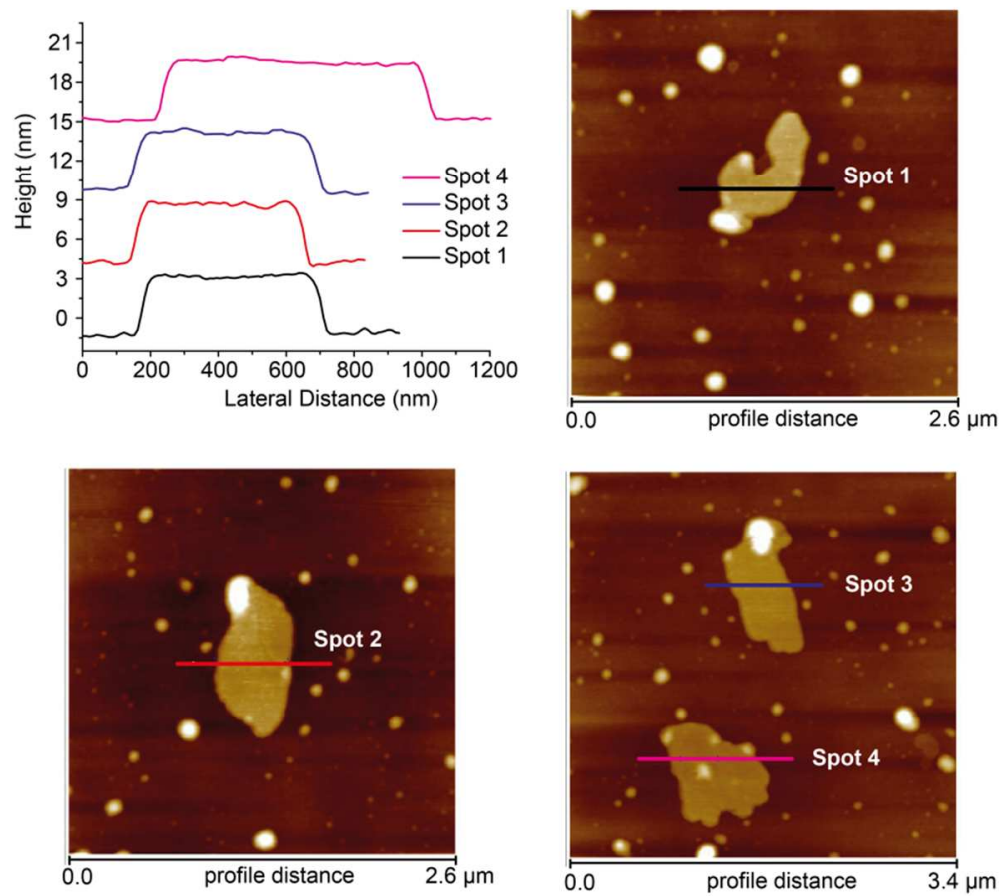

Figure S3. Supplemental AFM profiles of the nanosheet products, further supporting the uniform flatness of the sheets and the consistency of the $\sim 4.5 \mathrm{~nm}$ height profile 


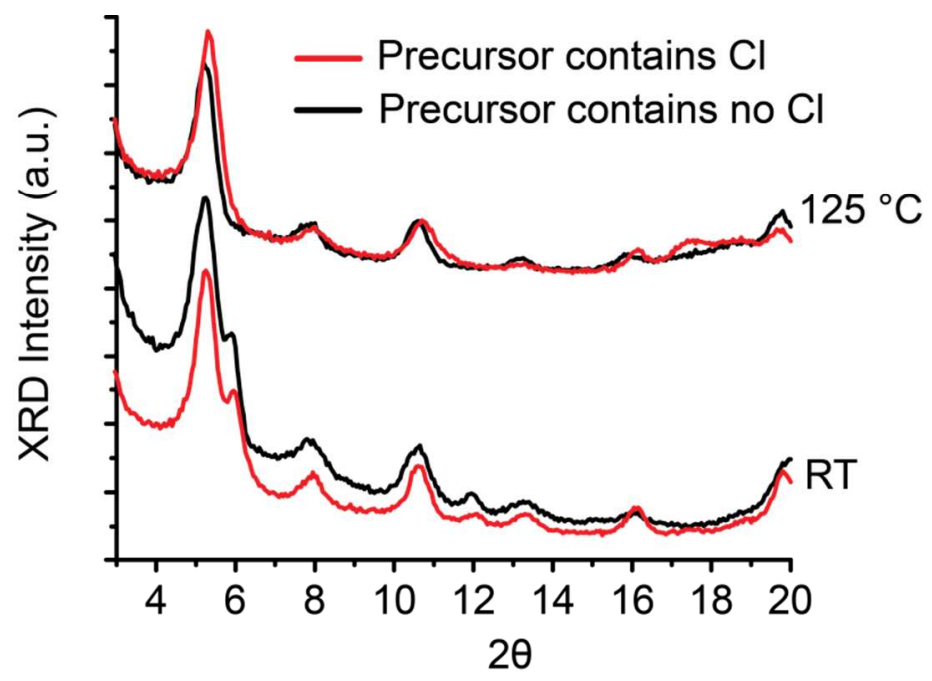

Figure S4. Comparison of $\mathrm{CuSC}_{10} \mathrm{H}_{20} \mathrm{COOH}$ precursor with and without $\mathrm{Cl}^{-}$, shown at room temperature (RT) and at $125^{\circ} \mathrm{C}$. This data shows the $2 \theta=6,12^{\circ}$ peaks attributed to a stacking defect present in both samples decreased as the samples were brought to $125^{\circ} \mathrm{C}$ 